NBER WORKING PAPER SERIES

\title{
SHOULD WE TAX SUGAR-SWEETENED BEVERAGES? AN OVERVIEW OF THEORY AND EVIDENCE
}

\author{
Hunt Allcott \\ Benjamin Lockwood \\ Dmitry Taubinsky \\ Working Paper 25842 \\ http://www.nber.org/papers/w25842 \\ NATIONAL BUREAU OF ECONOMIC RESEARCH \\ 1050 Massachusetts Avenue \\ Cambridge, MA 02138 \\ May 2019
}

We are grateful to David Frisvold, Anna Grummon, Gordon Hanson, Robert Inman, Daniel Reck, Alex Rees-Jones, Christina Roberto, Steven Sexton, and Timothy Taylor for helpful comments, and to Andrew Joung for excellent research assistance. We thank the Sloan Foundation and the Wharton Dean's Research Fund for grant funding. The views expressed herein are those of the authors and do not necessarily reflect the views of the National Bureau of Economic Research.

NBER working papers are circulated for discussion and comment purposes. They have not been peer-reviewed or been subject to the review by the NBER Board of Directors that accompanies official NBER publications.

(C) 2019 by Hunt Allcott, Benjamin Lockwood, and Dmitry Taubinsky. All rights reserved. Short sections of text, not to exceed two paragraphs, may be quoted without explicit permission provided that full credit, including $(\odot$ notice, is given to the source. 
Should We Tax Sugar-Sweetened Beverages? An Overview of Theory and Evidence Hunt Allcott, Benjamin Lockwood, and Dmitry Taubinsky

NBER Working Paper No. 25842

May 2019

JEL No. D00,D6,D9,H0

\begin{abstract}
$\underline{\text { ABSTRACT }}$
Taxes on sugar-sweetened beverages are growing in popularity and have generated an active public debate. Are they a good idea? If so, how high should they be? Are such taxes regressive? People in the U.S. and some other countries consume remarkable quantities of sugar-sweetened beverages, and the evidence suggests that this generates significant health costs. Building on recent work by Allcott, Lockwood, and Taubinsky (Forthcoming) and others, we review the basic economic principles that determine the socially optimal SSB tax. The optimal tax depends on (1) externalities: uninternalized health system costs from diseases caused by sugary drink consumption; (2) internalities: costs consumers impose on themselves by consuming too many sugary drinks due to poor nutrition knowledge or lack of self-control; and (3) regressivity: how much the financial burden and the internality benefits from the tax fall on the poor. We summarize the empirical evidence about the key parameters affect how large the tax should be. In the theoretical framework of Allcott, Lockwood, and Taubinsky (Forthcoming), our calculations imply that sugar-sweetened beverage taxes are welfare enhancing, and indeed that the optimal nationwide SSB tax rate may be higher than the one cent per ounce rate most commonly used in U.S. cities. Using our theoretical framework, we end by deriving seven concrete implications for optimal SSB tax structure.
\end{abstract}

Hunt Allcott

Department of Economics

New York University

19 W. 4th Street, 6th Floor

New York, NY 10012

and NBER

hunt.allcott@nyu.edu

Benjamin Lockwood

The Wharton School

University of Pennsylvania

1400 Steinberg-Dietrich Hall

3620 Locust Walk

Philadelphia, PA 19104

and NBER

ben.lockwood@wharton.upenn.edu
Dmitry Taubinsky

University of California, Berkeley

Department of Economics

530 Evans Hall \#3880

Berkeley, CA 94720-3880

and NBER

dmitry.taubinsky@berkeley.edu 
"Sin taxes" are imposed to discourage individual behaviors, such as smoking or drinking alcohol, that are thought to harm the individual and possibly others in society. This paper provides an economic framework for evaluating an increasingly popular class of sin taxes: those on sugar-sweetened beverages. As of mid2019, seven U.S. cities and 39 countries around the world have implemented sugar-sweetened beverage taxes, mostly in the past few years (GFRP 2019).

Proponents of these taxes point to a range of policy goals, including improving public health and raising revenues that can be used to reduce budget deficits or fund social programs. Opponents often express concerns about paternalistic government intervention in individual decisions and point out that sugar-sweetened beverages are consumed most heavily by the poor, which could make taxes regressive. How do economists evaluate these arguments? Should we tax sugar-sweetened beverages? If so, how high should the tax be?

In the first part of the paper, we provide background on sugar-sweetened beverage consumption patterns and the resulting health harms. This section helps to explain why sugary drinks have come to be seen as a "sin" worthy of taxation. In the second part of the paper, we draw on our recent work (Allcott, Lockwood, and Taubinsky, Forthcoming) to present the economic principles that determine the optimal level of sugar-sweetened beverage taxes. We discuss how the price elasticity of demand, externalities, "internalities," distributional concerns, and the incidence on producers all shape the optimal tax on sugar-sweetened beverages. In the third part of the paper, we summarize the growing empirical literature that estimates these key parameters.

We end with seven concrete implications of the economic framework that we summarize. First, minimizing sugary drink consumption will not achieve the same gains as optimally counteracting externalities and internalities. Second, it is most efficient to target policies to reduce consumption among people generating the largest externalities and internalities. Third, it is more efficient to tax grams of sugar, rather than ounces of liquid. Fourth, taxing diet drinks and fruit juice is efficient if and only if they also cause uninternalized health harms. Fifth, the regressivity of the tax depends on who has larger internalities, not just who pays more in taxes. Sixth, statewide implementation of taxes reduces the efficiency costs of leakage. Finally, in the context of the Allcott, Lockwood, and Taubinsky (Forthcoming) theoretical framework, the benefits of sugar-sweetened beverage taxes probably exceed their costs.

\section{Background: Taxes, Consumption, and Health Harms}

\section{Existing Sugar-Sweetened Beverage Taxes}

Table 1 presents the seven current city-level sugar-sweetened beverage taxes in the U.S., all of which have been enacted since 2014. Cook County, which contains the city of Chicago, passed and then repealed its tax a year later. The modal tax rate is 1 cent per ounce, although Boulder, Philadelphia, and Seattle have higher rates. In addition to these explicit taxes, 23 states plus the District of Columbia exempt or partially exempt groceries from sales taxes but do not include sugar-sweetened beverages as "groceries," thereby taxing these drinks at a higher rate (Loughead, 2018). Table 2 maps the 39 other countries around the world with sugar-sweetened beverage taxes.

A sugar-sweetened beverage is any drink with caloric sweeteners, including carbonated soft drinks, sports drinks, energy drinks, fruit drinks, chocolate (or otherwise sweetened) milk, and sweetened coffee and tea, but not including 100 percent fruit juice or "diet" drink alternatives with non-caloric sweeteners. The beverage categories included in sugary drink taxes depend both on political calculations and judgment calls by public 
Table 1: Sugar-Sweetened Beverage Taxes in U.S. Cities

\begin{tabular}{cccc}
\hline Location & Date enacted & $\begin{array}{c}\text { Tax rate } \\
\text { (\$ per ounce) }\end{array}$ & $\begin{array}{c}\text { Includes } \\
\text { diet drinks? }\end{array}$ \\
\hline Albany, CA & November 2016 & 1 & No \\
Berkeley, CA & November 2014 & 1 & No \\
Boulder, CO & November 2016 & 2 & No \\
Oakland, CA & November 2016 & 1 & No \\
Philadelphia, PA & June 2016 & 1.5 & Yes \\
San Francisco, CA & November 2016 & 1 & No \\
Seattle, WA & June 2017 & 1.75 & No \\
Cook County & November 2016 (repealed October 2017) & 1 & Yes \\
\hline
\end{tabular}

Table 2: Sugar-Sweetened Beverage Taxes Around the World

\begin{tabular}{cccc}
\hline Europe & Western Pacific & $\begin{array}{c}\text { Africa, Eastern Mediterranean, } \\
\text { and Southeast Asia }\end{array}$ & Americas \\
\hline Estonia (2018) & Phillippines (2018) & Morocco (2019) & Colombia (2019) \\
Ireland (2018) & Brunei (2017) & South Africa (2018) & Bermuda (2018) \\
United Kingdom (2018) & Vanuatu (2015) & Bahrain (2017) & Peru (2018) \\
Portugal (2017) & Kiribati (2014) & India (2017) & Barbados (2015) \\
Belgium (2016) & Cook Islands (2013) & Maldives (2017) & Dominica (2015) \\
France (2012) & Tonga (2013) & Sri Lanka (2017) & Chile (2014) \\
Hungary (2011) & Fiji (2007) & Saudia Arabia (2017) & Mexico (2014) \\
Latvia (2004) & Nauru (2007) & Thailand (2017) & \\
Norway (1981) & Palau (2003) & United Arab Emirates (2017) & \\
Finland (1940) & French Polynesia (2002) & St. Helena (2014) & \\
& Samoa (1984) & Mauritius (2013) & \\
& &
\end{tabular}

Notes: Countries with taxes on sugar-sweetened beverages; year of implementation in parentheses. This figure is based on data from the Global Food Research Program (2019).

health experts. All city-level taxes in Table 1 cover all sugar-sweetened beverages except for sweetened milk products, and they do not include $100 \%$ fruit juice, on the grounds that the vitamins and nutrients such as calcium in these drinks provide some additional nutritional value. The Philadelphia and Cook County taxes additionally included diet drinks. As we discuss later, it is not clear that these coverage decisions are socially optimal.

\section{Sugar-Sweetened Beverage Consumption}

Americans consume a remarkable amount of calories from sugar-sweetened beverages. A typical 12-ounce soft drink might contain 35-40 grams of sugar and about 140 calories, representing about 7 percent of a benchmark 2000-calorie-per-day diet. Using data from the National Health and Nutrition Examination Survey (NHANES) for years 2009-2016, we calculate that the average American adult consumes 154 calories per day from sugar-sweetened beverages, which represents 6.9 percent of actual total calorie intake. Almost all of these calories are from added sugars. As a benchmark, the U.S. Dietary Guidelines recommend limiting added sugars from all food and drinks to no more than 10 percent of total calorie intake, or around 200 calories per day, while the World Health Organization is even more conservative. In the NHANES data, sugar-sweetened beverages account for 23 percent of the average American adult's total sugar consumption.

Sugary drinks are broadly popular: about 50 percent of American adults consume at least one sugarsweetened beverage on any given day. However, Figure 1 shows that consumption varies substantially by 
Figure 1: Sugar-Sweetened Beverage Consumption by Income

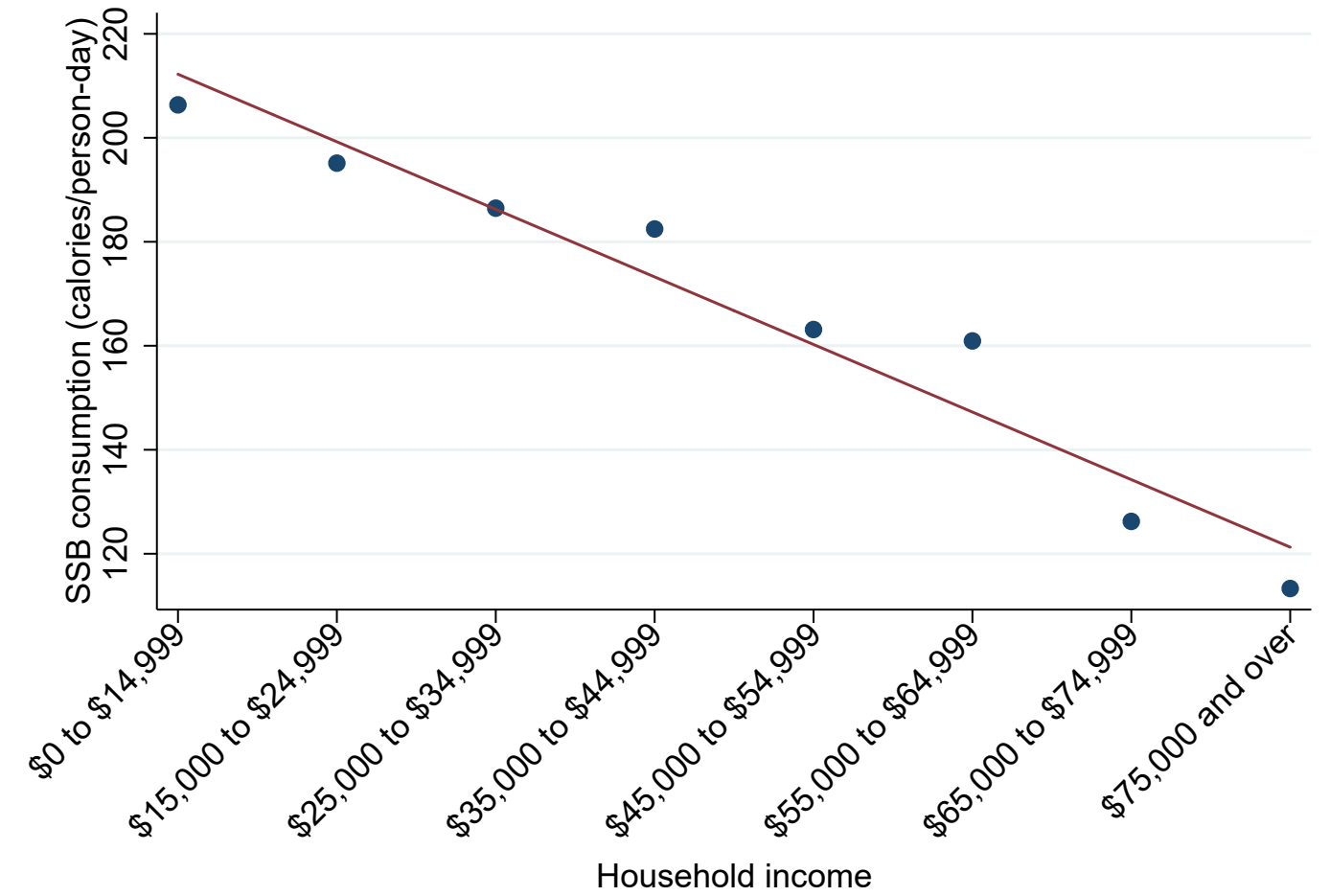

Notes: This figure shows average sugar-sweetened beverage consumption by household income, as measured by the National Health and Nutrition Examination Survey for years 2009-2016.

income. People with household income below $\$ 25,000$ per year consume 200 calories per day of sugarsweetened beverages, while people with household income above $\$ 75,000$ per year consume only 117 calories per day. This generates the concern that taxes on sugar-sweetened beverages could be regressive. There is also substantial within-group variation: in a large nationwide survey carried out by Nielsen for Allcott, Lockwood, and Taubinsky (Forthcoming), the 90th percentile of individual consumption is 2.7 times larger than the mean, and 6.5 times the median.

Perhaps due to rising public awareness of the health effects of sugar-sweetened beverages, consumption is falling over time in the United States and many other western countries. In the NHANES data, the average American consumed 205 calories per day from sugar-sweetened beverages in 2003-2004, compared to 154 calories in 2009-2016. Popkin and Hawkes (2016) find that sugar-sweetened beverage calorie consumption per capita declined from 2009-2014 in North America, Australasia, and Western Europe, but increased in the rest of the world. They also report that North Americans consume 3-4 times more calories from sugar-sweetened beverages than the world average .

\section{Health Harms from Sugar-Sweetened Beverage Consumption}

Sugar-sweetened beverage consumption harms health through three main channels: weight gain, type 2 diabetes, and cardiovascular disease. (We will not discuss other health effects such as tooth decay.) For these main channels, we briefly discuss evidence on the magnitude of the effects. Some of this evidence is from non-randomized epidemiological studies that correlate sugar-sweetened beverage consumption with health 
outcomes, while attempting to control for confounding variables. While this is sometimes the only evidence available, correlation doesn't imply causation: additional unmeasured confounders such as eating patterns, exercise, and social conditions could mean that these conditional correlations are inaccurate measures of the causal effect of sugar-sweetened beverage consumption on health. Moreover, most quantitative studies report only an average effect, though the effects may be concentrated on particular groups or heavy users.

The first main health harm is weight gain. Some evidence suggests that sugary drinks cause more weight gain than equally sugary foods because calories are less satiating in liquid form (Pan and Hu, 2011). A randomized experiment by Mourao, Bressan, Campbell, and Mattes (2007) found that when people consume the same amount of calories from solid foods instead of liquids (say, jelly beans instead of soda, or cheese instead of milk), they eat less later in the day, resulting in significantly lower overall calorie intake. Other experiments have found that when people are provided with the same foods and either caloric or non-caloric beverages, they consume the same amount of calories from food regardless of the beverage provided and report no difference in feelings of satiety (DellaValle, Roe, and Rolls 2005; Flood, Roe, and Rolls 2006).

Both field experiments and non-experimental analyses have estimated the weight gain effects. Randomized trials with children and adolescents find that substituting diet drinks instead of sugar-sweetened beverages for 12-18 months reduces weight by 2-4 pounds (Ebbeling, Feldman, Chomitz, Antonelli, Gortmaker, Osganian, and Ludwig, 2012; de Ruyter, Olthof, Seidell, and Katan, 2012). In observational analysis of three adult cohort studies, Mozaffarian, Hao, Rimm, Willett, and $\mathrm{Hu}$ (2011) find that one serving per day additional sugar-sweetened beverage consumption is conditionally associated with weight gain of one pound per four-year follow-up period, controlling for a variety of biological and lifestyle factors. ${ }^{1}$

The second main health harm is type 2 diabetes. Sugar-sweetened beverages have high "glycemic loads," meaning that they contain large amounts of rapidly digestible sugars. Sugars are digested more quickly when they come from drinks than when they are eaten with food. When foods or drinks with high-glycemic loads are digested, they prompt a quick release of glucose into the bloodstream and the secretion of a corresponding amount of insulin in response. Over time, these states of elevated blood glucose and insulin can cause insulin resistance, often a precursor to diabetes (see description in Ludwig 2002; Raben, Møller, Flint, Vasilaras, Christina Møller, Juul Holst, and Astrup 2011). A meta-analysis of 17 cohort studies found that drinking one more serving of sugar-sweetened beverages per day was associated with a 13 percent higher risk of developing type 2 diabetes (Imamura et al., 2015; see also Malik, Popkin, Bray, Després, Willett, and Hu 2010).

The third main health harm is cardiovascular diseases, such as heart attack and narrowing of the arteries. Randomized trials show that diets high in sugar and other refined carbohydrates increase blood pressure and cholesterol, which are precursors to cardiovascular disease (Santos, Esteves, da Costa Pereira, Yancy Jr, and Nunes, 2012; Te Morenga, Howatson, Jones, and Mann, 2014). A meta-analysis of four studies found that consuming one additional sugar-sweetened beverage per day is associated with 17 percent higher risk of coronary heart disease (Xi, Huang, Reilly, Li, Zheng, Barrio-Lopez, Martinez-Gonzalez, and Zhou 2015).

This background helps explain why the public health community has focused on taxing sugary drinks instead of a broader sugar tax including sugar in foods: sugar consumed through drinks is more harmful.

\footnotetext{
${ }^{1}$ For a review of additional randomized experiments of the effects of sugar-sweetened beverages on weight gain, see Mattes, Shikany, Kaiser, and Allison (2011). For reviews of cohort studies, see Vartanian, Schwartz, and Brownell (2007) and Malik, Pan, Willett, and $\mathrm{Hu}$ (2013). Weight gain is thought to independently affect diabetes and cardiovascular disease in addition to the mechanisms described below, and weight mediates the statistical relationships between sugar-sweetened beverage consumption and those conditions (for example, Schulze, Manson, Ludwig, Colditz, Stampfer, Willett, and Hu 2004; Fung, Malik, Rexrode, Manson, Willett, and $\mathrm{Hu} 2009)$.
} 


\section{Quantifying Health System Costs}

By combining estimates of the price elasticity of demand for sugar-sweetened beverages, the effect of sugarsweetened beverages on diabetes, cardiovascular disease, and obesity, and the costs of treating these diseases, it is possible to estimate the effects of a sugar-sweetened beverage tax on health care costs. The necessary parameters are often estimated from correlation studies and are thus subject to the same important caveat that correlation does not imply causation. Wang, Coxson, Shen, Goldman, and Bibbins-Domingo (2012) estimate that over 10 years, a one cent per ounce tax would save $\$ 17.1$ billion in health care costs. Using a separate model, Long, Gortmaker, Ward, Resch, Moodie, Sacks, Swinburn, Carter, and Wang (2015) estimate the 10-year savings to be $\$ 23.6$ billion.

\section{An Economic Framework for Evaluating Sugar-Sweetened Beverage Taxes}

The economic logic behind a tax on sugar-sweetened beverages builds from the classic principles of externalitycorrecting taxes (Pigou 1920): if consuming a good harms others, then people will consume too much if the market is not regulated. Thus, a tax imposed on a good with negative externalities can raise welfare by reducing consumption toward the efficient level at which marginal social cost equals marginal social benefit.

Additionally, a growing body of research in behavioral economics indicates that people sometimes ignore harmful or beneficial effects to themselves - for example, because they are misinformed, or because they do not fully consider future health consequences due to "present focus." These costs are sometimes called "internalities," and we view their presence as a key distinction of "sin taxes" on goods like cigarettes and alcohol.

It is important to emphasize that externalities and internalities are not the same as "health harms." A consumer might rationally drink something (or take any other action) despite the health risks, because her enjoyment of the drink outweighs the health harms. What matters for sin taxes is whether consumers' choices impose harms on others (externalities) or harms on themselves that they do not correctly internalize (internalities).

Although internality and externality costs operate somewhat similarly, there are important differences between the two, and we consider each in turn. Figure 2, which illustrates the effect of a sugar-sweetened beverages tax on demand from a single consumer can be used to discuss both concepts. In Allcott, Lockwood, and Taubinsky (Forthcoming), we provide a formal treatment of the issues this section.

\section{Welfare Effects Due to Externalities}

Some sin goods generate direct consumption externalities - cigarettes create second-hand smoke, for example. In the context of sugar-sweetened beverages, the most important externalized cost is probably in the form of financial health care costs which are shared through public or private insurance. Strictly speaking, these are moral hazard costs or "fiscal externalities" (in the case of public insurance) which arise due to preexisting information frictions in a second-best world. We will call all such externalized costs "externalities," however, to emphasize that they are borne by people other than the sugar-sweetened beverage consumer.

Using Figure 2 to illustrate the role of externalities, $D_{1}$ plots the individual's demand curve for sugarsweetened beverages at various prices (or, equivalently, the consumer's marginal private benefit from sugary drinks at each quantity). The vertical distance $b$ represents the per-unit externality cost, so that $D_{2}$ plots 


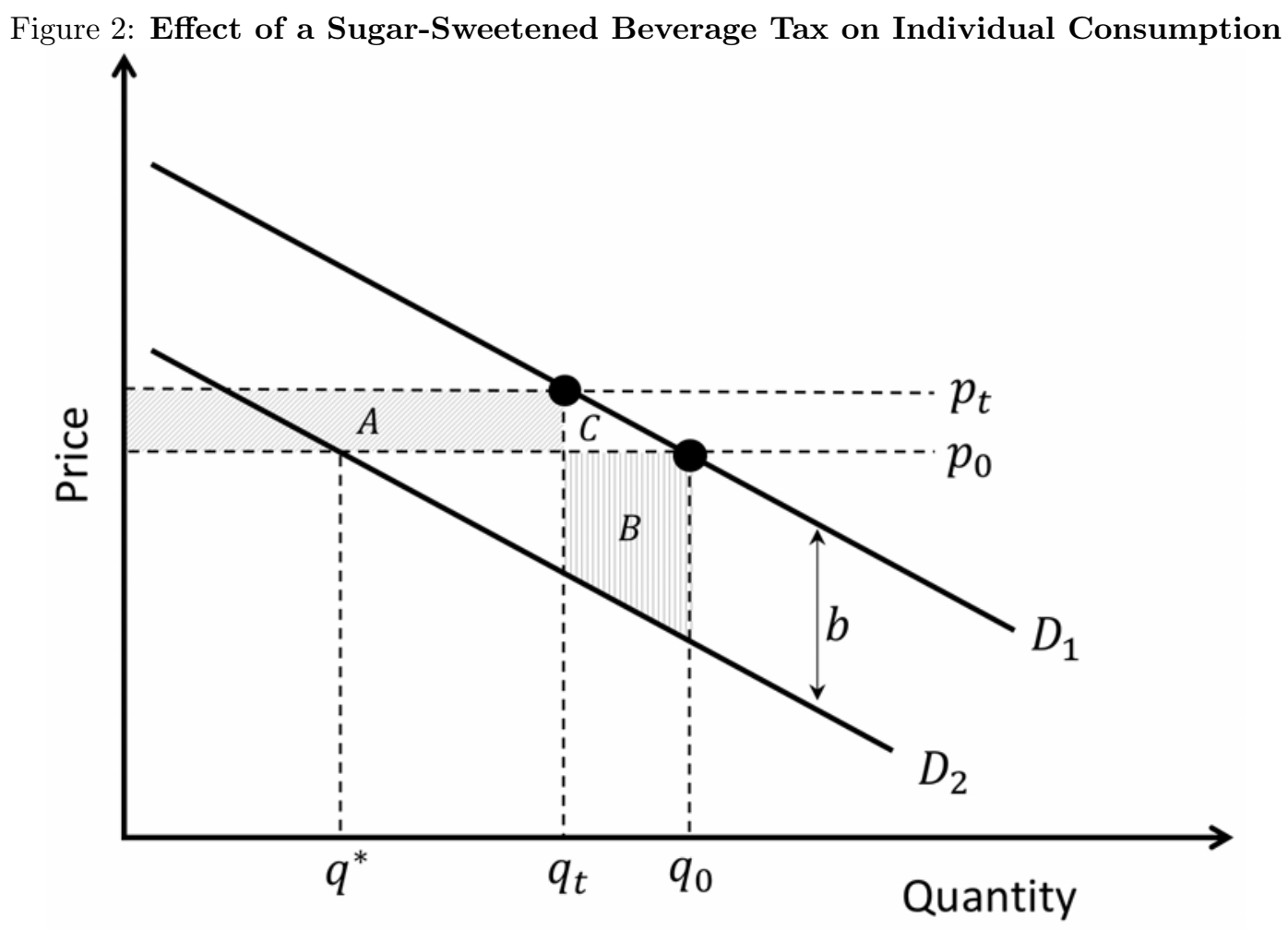

the marginal social benefit to consumers, net of externalities, as a function of quantity consumed. (In practice, $b$ may vary with the level of consumption; here we plot it as a constant marginal externality for simplicity.) A tax that raises the price from $p_{0}$ to $p_{t}$ then has three distinct effects on welfare. The area $A=t \times q_{t}$ is transferred from the consumer to the government, in the form of tax revenue. The area $C=\Delta q \times t / 2$ represents a further decrease in the consumer's welfare from foregone sugary drink consumption due to the tax. The area $B+C=\Delta q \times b$, represents an increase in welfare for those bearing the externality. In the context of sugar-sweetened beverages, a natural benchmark assumption is that the externality reduction accrues to the government's budget (in present value terms) - for example due to reduced Medicare expenditures on treatments for conditions such as heart disease and diabetes. Therefore the net effect of the tax is twofold: a transfer of $A+C$ from the consumer to the government, and a further increase in government funds of $B$.

The total welfare effects of an externality-based sugar-sweetened beverage tax depend on aggregating these components across individuals. Because the tax involves transfers between parties, something must be assumed about the social value of resources in the hands of the government relative to consumers, and across consumers of different types. A common assumption is that the marginal utility from consumption is decreasing with consumers' incomes - the same assumption that is often used to justify progressive income tax schedules. One way to capture such distributional implications is to assign "social marginal welfare weights" (as in Saez and Stantcheva 2016) to different households depending on their income (or possibly other attributes), so that a weight of, say, 1.5 on household $x$ implies that society places the same value on $\$ 1$ in the hands of household $x$ as on $\$ 1.50$ in the hands of the government. Then the transfer $A+C$ from the consumer to the government generates a net a social gain if the weight of on the consumer in question is less than 1 , and a social loss otherwise. 
Putting these pieces together, we aggregate these effects by summing the externality benefit $B$ and the transfer $A+C$ across consumers, weighted appropriately. The area $B$ scales with its width (proportional to the individual elasticity of demand for sugary drinks) multiplied by its height (the externalized health costs sugary drink consumption). Therefore the average value of $B$ across all consumers is proportional to the average demand elasticity times the average externality, plus the covariance of the two. This covariance term reflects the fact that if consumers who generate the largest externalities are most responsive to a tax, then the externality benefits of a corrective tax are larger.

The transfer $A+C$ has the same height for all consumers $\left(p_{t}-p_{0}\right)$, but its width depends on the quantity of sugary drinks consumed by each consumer. Moreover, this summation across consumers is weighted by the difference between their welfare weight and the value of public funds. In theory, the sign of this welfare effect can be either positive or negative, but it will tend to be negative if poorer consumers (those with high welfare weights) tend to purchase more of the externality-producing good, as is the case for sugar-sweetened beverages. The welfare effect of this transfer depends on the level of sugary drink consumption across the income distribution, and not on sugary drink consumption as a share of consumers' income. Thus, this approach accounts for the common concern that sugar-sweetened beverage taxes may be regressive.

\section{Welfare Effects Due to Internalities}

In the context of sugar-sweetened beverages, there are two main reasons why consumers might not act in their own best interest. First, consumers may have imperfect information, and thus they may not know how sugar-sweetened beverages can harm their health. Of course, information provision, such as educational campaigns and disclosure requirements studied by Moran and Roberto (2018); Cantor, Torres, Abrams, and Elbel (2015); Bollinger, Leslie, and Sorensen (2011); Grummon, Tallie, Golden, Hall, Ranney, and Brewer (2019b); and others, is the direct way to address imperfect information. However, unless these policies fully inform all consumers, there is a role for taxes as a complementary policy tool.

Second, consumers may face problems of self-control and time-inconsistency, and thus might underweight the future health costs of consumption of sugar-sweetened beverages relative to how they would like to weight those costs in the future. There is disagreement as to whether policymakers should respect consumers' "longrun" or "short-run" preferences (Bernheim and Rangel 2009; Bernheim 2016; Bernheim and Taubinsky 2018). A social planner who uses the long-run criterion for welfare analysis might want to help people implement their long-run preferences by reducing consumption of sugar-sweetened beverages.

We can reinterpret Figure 2 to illustrate internalities (assuming away externality costs for the moment), with $D_{1}$ representing the consumer's observed demand curve, and $D_{2}$ representing the latent demand curve that would arise if consumers did not suffer from internalities. Then the vertical distance $b$ represents an ignored internality cost, measured in money units.

Internalities operate similarly to externalities, with one important difference: the area $B+C$ accrues to the consumer, rather than to the bearer of the externality (the government in our earlier example). This does not change the interpretation of the transfer $A$, from the individual to the government, which will again take on a more negative value if poorer consumers purchase more sugar-sweetened beverages. And the area $C$ can be regarded as a transfer from consumers affected by the tax to themselves, so for social welfare purposes it can be ignored. However, it does change the interpretation of $B$, which (unlike in the case of externalities) is multiplied by the individual's welfare weight. As a result, for a given average size of the internality, the internality correction benefits from the tax are larger to the extent that poorer consumers have larger areas of $B$. This will be the case either if internalities are larger for poor consumers (e.g., due to poorer access to 
information or more exposure to settings that demand and deplete self-control), or if their demand response $\Delta q$ is higher (e.g., if the elasticity of demand is constant across consumers, since the poor consume a higher level). In other words, internality benefits from a sugary drink tax are theoretically likely to be progressive, even if the financial costs are regressive.

\section{Putting it Together}

In a context with both externalities and internalities, one must add the externality and (welfare-weighted) internality benefits, netted against any welfare effects due to the transfer of resources from consumers to the government. Externality benefits depend (positively) on the aggregate elasticity of demand for sugarsweetened beverages, the average externalized health cost from consumption, and their covariance. Internality benefits similarly depend on the aggregate elasticity and average uninternalized health costs, as well as the extent to which uninternalized health costs and demand responses are higher among poor consumers. Finally, the welfare cost of the resource transfer is larger to the extent poor households consume more sugary drinks.

\section{Are Sugar-Sweetened Beverage Taxes "Regressive"?}

A common concern about sugar-sweetened beverage taxes is that they may hurt poor households, since low earners tend to purchase more sugary drinks. The concepts of externalities, internalities, and transfers from Figure 2 illustrate the basic forces at work.

To understand who is helped and hurt by a sugar-sweetened beverage tax, we need to draw a distinction between who pays the most in taxes and who is benefited or harmed, all things considered. While it is true that poorer consumers will pay more in taxes on average (due to their disproportionate sugary drink consumption), if there are internality costs from consuming sugary drinks, the beneficial reductions of health conditions like heart disease and diabetes will also accrue to low income households, as highlighted by Gruber and Köszegi (2004). In terms of Figure 2, although poorer consumers incur more costs due to area $A$ on average, those may be offset (partially, or more-than-fully) by the gained area $B$. As a result, the fact that poorer consumers purchase more sugar-sweetened beverages does not necessarily imply that they are made worse off by the tax. The extent of this offset depends on the price elasticity of demand: if consumers substantially reduce sugar-sweetened beverage consumption in response to a tax, then the corrective benefits are large relative to the financial burden, making the tax less regressive. On the other hand, if a tax has little effect on consumption, then the corrective benefits are relatively small.

A related question is how the profile of consumption by income affects the optimal size of the tax. This depends on why consumption varies with income. Do people have the same underlying preferences, so differences in consumption across incomes are due to the causal effect of more or less income? Or do people at different income levels have systematically different preferences, so they would consume different amounts even if their incomes were all reset to the same level? A classic principle of optimal taxation (Atkinson and Stiglitz, 1976) holds that if differences in consumption of sugary drinks (or any other good) are driven by causal income effects, then they should not be taxed or subsidized for redistributive purposes - such redistribution is more efficiently carried out through the income tax. In contrast, if differences in sugary drink consumption are driven by between-income preference heterogeneity, then that consumption serves as a "tag," which is useful for redistribution, reducing the optimal sugary drink tax. In Allcott, Lockwood, and Taubinsky (Forthcoming), we find that preference heterogeneity appears to be the reason why low-income 
people drink more sugar-sweetened beverages.

Finally, the total regressivity of a sugar-sweetened beverage tax may depend on how the resulting revenues are allocated. Some existing policies have earmarked revenues toward causes that primarily benefit lowincome households - sometimes called "progressive revenue recycling." In Philadelphia, for example, a portion of sugar-sweetened beverage tax revenues are pre-allocated to expanding pre-kindergarten education services within the city. Although earmarking may be useful for building popular support for sugary drink taxes, from a theoretical perspective the practice does not alter the size of the optimal tax. To the extent that it is beneficial to target funds toward pre-kindergarten programs - or to make the income tax-and-transfer schedule more progressive generally - then that should be done regardless of whether a sugar-sweetened beverage tax is implemented. As a result, revenue recycling and earmarking may be better interpreted as questions of political expediency, rather than optimal taxation. Moreover, pre-allocation may create challenges for policymakers if the tax turns out to be more effective than expected at reducing sugary drink consumption, resulting in a budget shortfall for popular or progressive programs.

\section{Substitution and Leakage}

So far, we have assumed that sugar-sweetened beverages can be modeled as one homogeneous good with no substitutes or complements. In reality, this is not the case, and this generates additional important considerations.

First, there are many thousands of different sugar-sweetened beverages, each with different sugar content. Theoretically, the optimal structure would be to impose separate taxes on each good, depending on the parameters described above (internalities, externalities, causal income effects, and between-income preference heterogeneity). In practice, these parameters are difficult to estimate for each specific good, and such heterogeneous taxes would be prohibitively difficult to administer.

Most existing sugar-sweetened beverage taxes therefore use a simplified structure of a constant tax rate per ounce of drink. However, since the externalities and internalities from sugary drinks come from the sugar, not the liquid, the externalities and internalities are likely to be proportional to the sugar content of beverages. An alternative simple tax structure of a constant tax rate per gram of sugar in the drink would much more closely approximate the theoretical optimum.

Second, when consumers cut back on sugar-sweetened beverages due to the tax, they may also raise or lower their consumption of other (untaxed) sugary goods. To the extent that they do, the resulting change in externalities and internalities from those goods should be considered when setting the tax on sugarsweetened beverages. The sign of this effect is ambiguous. For example, consumers may view sugary snacks as a substitute for sugar-sweetened beverages - an alternative way to get a desired "sugar kick" - in which case some of the internality and externality reductions from a tax on sugar-sweetened beverages may be offset by increased internalities and externalities from substitution to other sugary goods. On the other hand, sugar-sweetened beverages and unhealthy foods may be complements, and if consumers tend to purchase or consume such snacks together, then the analysis above will understate the benefits of a sugary drink tax.

A third reason substitution may matter is that consumers may adjust their behavior to evade or avoid a sin tax - for example, through black market cigarette or drug purchases or, in the case of city-level beverage taxes, through cross-border shopping. Avoidance measures create costs for consumers without reducing externalities and internalities from sugar-sweetened beverage consumption. As a result, although some local tax experimentation is useful for estimating the effects of a tax, in the long run there is a benefit from harmonizing tax rates to reducing avoidance, by setting them at the state or regional level. 


\section{Pass-Through and Producer Surplus}

The exposition so far accounts only for the consumer side of the market, and therefore leaves out two key issues: the question of tax pass-through (what portion of the tax is borne by consumers in the form of a price increase), and producer surplus, which accrues to firm owners (in the form of profits) or to employees. To illustrate these forces, Figure 3 depicts a simple supply and demand model of the market for sugar-sweetened beverages. $D_{1}^{m}$ represents observed market demand for sugar-sweetened beverages, while $b^{m}$ represents the average marginal externality (weighted by elasticities of demand) plus average marginal internality (weighted by elasticities of demand and welfare weights), so that $D_{2}^{m}$ represents market demand less the uninternalized social cost of consumption (normalized by the marginal value of public funds) at each quantity. For illustrative purposes, the pictured tax is a little lower than the optimal level, $b^{m}$.

In a simple model like this one, the conventional explanation for incomplete tax pass-through is that some of the tax incidence falls on producers, rather than consumers. To account for this possibility, we allow for a market supply curve $S$ that slopes upward, for example due to rising marginal costs. The share of the tax that is passed through to consumers is $\frac{p_{t}-p_{0}}{t}$ - a quantity which rises with the elasticity of sugary drink supply and falls with the (absolute) elasticity of demand. The tax then has three distinct effects on welfare: a transfer from producer surplus to the government, represented by the vertically-hatched area $X$; a transfer from consumers to the government, represented by the horizontally-hatched area $Y$; and a beneficial reduction in externalities and internalities (now combined), represented by the angle-hatched area $Z$.

Relative to a model with infinitely elastic supply of sugary drinks (corresponding to full pass-through to consumers), the key difference is that some of the costs of the tax are borne by producers, rather than consumers. If marginal resources are valued equally in the hands of producers and (welfare-weighted) consumers of sugar-sweetened beverages, the issue of pass-through is irrelevant - the tax should be adjusted maximize the welfare gain from the internality and externality benefit $Z$, and the weighted transfer of resources $X+Y$. On the other hand, if resources are valued more in the hands of consumers than producers of sugar-sweetened beverages - for example, if marginal resources accrue to firm shareholders who have a lower average welfare weight than consumers of sugar-sweetened beverages (e.g., because they are richer) - then a lower pass-through will imply a larger net welfare benefit from the tax, and a higher tax at the optimum. Conversely, if a higher welfare weight is placed on producers, then partial pass-through calls for a lower sugar-sweetened beverage optimal tax.

Other explanations for partial pass-through - such as discrete pricing policies by grocers or an inability to separately price regular and diet soda fountain sales at fast-food restaurants - might generate different implications. In particular, if a portion of the tax is absorbed by producers with no reduction in quantity supplied, then the optimal tax may need to be larger than $b^{m}$ in order to achieve the efficient reduction in sugary drink consumption. However, this possibility depends on understanding the reason for partial pass-through, in addition to quantifying the pass-through rate itself.

\section{Empirical Estimates of Key Parameters}

In this section, we review the empirical estimates of the key parameters identified in the previous section, with an eye to the strengths and weaknesses of different estimation strategies. 
Figure 3: Effect of a Sugar-Sweetened Beverage Tax on Market Consumption

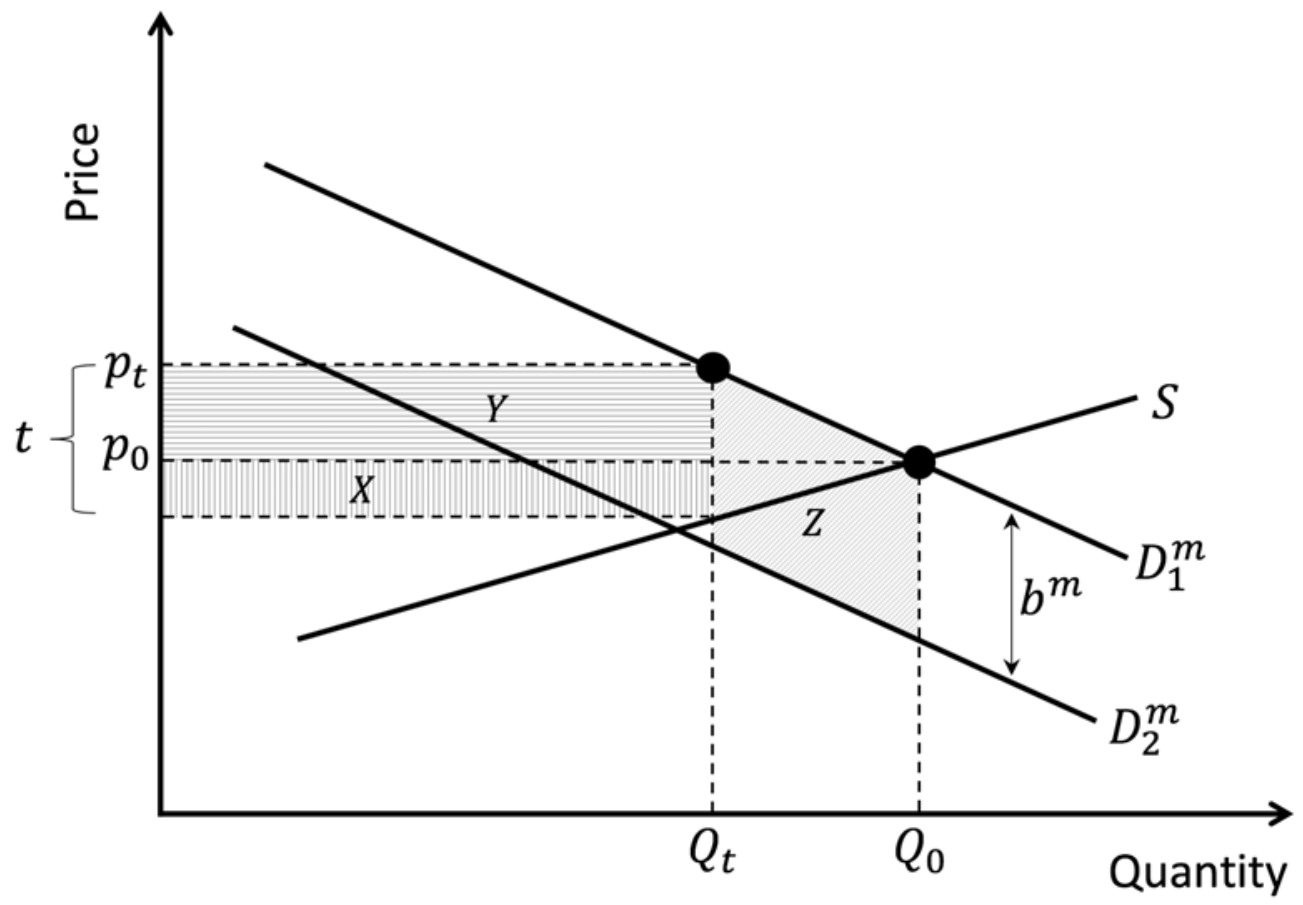

\section{Demand Elasticities}

When estimating demand for any good - not just sugar-sweetened beverages - perhaps the most basic challenge is to isolate quasi-random price variation in order to estimate the demand curve. Conceptually, a demand curve reflects the causal effect of prices on quantity purchased, not just the correlation between prices and quantity purchased. The ideal way to estimate a demand curve would be to run an experiment in which different consumers are offered different prices, and measure the share of consumers that buy at each price. In market data that do not include randomized pricing experiments, there are several forces that mean that correlation doesn't imply causation. For example, measurement error in prices can also incorrectly make demand appear to be less responsive to price than it actually is. As another example, retailers naturally charge higher prices for higher-quality goods, and also higher prices for the same good in periods of high demand. This "simultaneity bias" can sometimes even generate positive correlations between price and quantity demanded, whereas the true causal relationship is negative.

There are two types of strategies for isolating quasi-random variation in non-experimental data. The first is to attempt to control for product quality and demand fluctuations, in hopes that the remaining price variation is quasi-random. For example, Dubois, Griffith, and O'Connell (2017) include brand, time, and other fixed effects, thereby identifying the demand elasticity only off of variation in prices of the same product across retailers and variation in the slope of non-linear pricing (the relative prices of small vs. large containers) across brands. The second strategy is to find a useful instrumental variable for exogenous price movements. In Allcott, Lockwood, and Taubinsky (Forthcoming), we create an index of the price households pay for the specific sugar-sweetened beverages they buy at the specific stores where they shop, and we instrument for that price with the time-varying prices that the same retailer charges for the same 
beverages at other stores in other counties. Finkelstein, Zhen, Bilger, Nonnemaker, Farooqui, and Todd (2013) instrument for a household's price paid with prices paid by other households in the same city and quarter, excluding households living in the household's Census tract.

For sugar-sweetened beverages, data availability is a particular challenge. There are two common types of datasets. The first is household-level scanner data, such as the U.S. National Consumer Panel (also known as Homescan) or Kantar Worldpanel. Participating households are asked to scan the bar codes of all groceries that they bring home, but they do not record consumption away from home, such as purchases at restaurants, vending machines, and ballparks. This unobserved consumption can be substantial: in Allcott, Lockwood, and Taubinsky (Forthcoming), we estimate that total consumption exceeds Homescan grocery purchases by 39 percent. If sugar-sweetened beverage taxes are imposed on all consumption, then the relevant demand elasticity is for all consumption, including away from home. Consumption away from home could be more or less price elastic, and there may also be bias due to substitution if households respond to higher grocery prices by consuming more away from home.

The second type of dataset is self-reported consumption from beverage frequency questionnaires or dietary recall studies such as the National Health and Nutrition Examination Survey (NHANES), in which people record food and drink consumed over the past 24 hours or some other recent period. Self-reports may have more measurement error and do not track the same individuals over time, making it difficult to use the two strategies detailed above for isolating quasi-exogenous price variation.

There are several reviews of the literature estimating the price elasticity of demand for sugar-sweetened beverages. Andreyeva, Long, and Brownell (2010) report that across 14 studies, the mean price elasticity is -0.79 , with a range from -0.13 to -3.18 . Powell, Chriqui, Khan, Wada, and Chaloupka (2013) review 12 studies, finding a mean price elasticity of -1.21 , with range from -0.71 to -3.87 . In Allcott, Lockwood, and Taubinsky (Forthcoming), we estimate an elasticity of about -1.4. This relatively elastic demand implies that the internality and externality reduction benefits from a tax are meaningful relative to the burden of the tax payments.

A separate but related parameter is the elasticity of sugar-sweetened beverage consumption with respect to a tax. As illustrated in Figure 3, the tax elasticity depends on both the supply and demand elasticities. The tax elasticity is of interest because it determines the public health effect of a tax. Fletcher, Frisvold, and Teft (2010) study how consumption of sugar-sweetened beverages responds to changes in whether they are included in state sales and excise taxes, but this variation is very limited: among states with a non-zero tax during their sample period, the average tax rate was no more than about 5 percent. Bollinger and Sexton (2019), Cawley, Frisvold, Hill, and Jones (2018c), Silver, Ng, Ryan-Ibarra, Taillie, Induni, Miles, Poti, and Popkin (2017), Seiler, Tuchman, and Yao (2019), and others study responses to the Berkeley and Philadelphia taxes. While these tax rates are higher than the taxes studied by Fletcher, Frisvold, and Teft (2010), having only one or two cities limits the sample size and requires the strong assumption that no factors other than the tax change affected sugar-sweetened beverage demand. Tax elasticity estimates may also capture how interest groups' advertising campaigns and public debates about sin taxes could affect demand over and above the effect of a price increase (Rees-Jones and Rozema, 2018; Taylor et al., 2016).

\section{Externalities}

Sugar-sweetened beverage consumption generates two main types of externalities: health cost externalities and other fiscal externalities. Estimating the size of these externalities involves a series of challenges in measurement and causal inference. 
Health cost externalities result because most Americans have health insurance, typically through their employers, Medicare, or Medicaid, and thus most of the health costs caused by sugar-sweetened beverage consumption are paid for by others. Wang, Coxson, Shen, Goldman, and Bibbins-Domingo (2012) and Long, Gortmaker, Ward, Resch, Moodie, Sacks, Swinburn, Carter, and Wang (2015) both estimate that the health system costs of sugar-sweetened beverages are approximately 1 cent per ounce of sugar-sweetened beverage consumed. The U.S. Department of Health and Human Services estimates that for people with employer-provided insurance, about 15 percent of health costs are borne by the individual, while 85 percent are covered by insurance (Yong, Bertko, and Kronick 2011). Cawley and Meyerhoefer (2012) estimate that 88 percent of the total medical costs of obesity are borne by third parties. Putting these numbers together suggests that the average health cost externality from sugar-sweetened beverage consumption might be 0.8 to 0.9 cents per ounce.

This figure might overstate the true externality, because the results of Bhattacharya and Bundorf (2009; see also Bhattacharya and Sood 2011 in this journal) suggest that obese people who have employer-sponsored health insurance face the full health costs of obesity through lower wages. However, it is not clear whether these labor market effects also exist for less easily observable diseases such as diabetes and cardiovascular disease, and the results do not apply to people with government-sponsored health insurance through Medicare or Medicaid.

In addition to health cost externalities, sugar-sweetened beverage consumption imposes other fiscal externalities, i.e. positive or negative effects on the government's budget. As one tragic example, obesity appears to cause people to die earlier, reducing the amount of Social Security benefits that obese people will claim (Bhattacharya and Sood 2011; Fontaine, Redden, Wang, Westfall, and Allison 2003).

As described in the previous section, the key statistic is the average externality from sugar-sweetened beverage consumption for people who are marginal to the tax. While we have estimates of average externalities and overall demand elasticity, one additional important but unknown statistic is the covariance across people between the demand elasticity and the marginal health damages of sugar-sweetened beverage consumption. For example, low-income people are thought to be more price elastic, and their health cost externalities may be higher (if their health costs are not offset by wage reductions because they are on Medicaid) or lower (if they are more likely to be uninsured). Dubois, Griffith, and O'Connell (2017) argue that sugar-sweetened beverage consumption by young people might generate larger health harms, and they show that young people are more price elastic. Sugar-sweetened beverage consumption by people who are pre-diabetic - that is, just below the threshold for receiving diabetes treatment - may generate larger health cost externalities, since additional consumption may result in high health costs from managing type 2 diabetes. This covariance is one of many questions for future research.

\section{Internalities}

As with externalities, there are multiple challenges to measuring internalities. ${ }^{2}$ First, there is a mechanical tension in evaluating policies to address internalities, which are predicated on the idea that consumers $d o$ not act in their own best interest, using revealed preference techniques, which are predicated on the idea that consumers do act in their own best interest. Following Bernheim and Rangel (2009), behavioral welfare analyses must somehow establish a "welfare-relevant domain" - that is, a subset of consumer choices that

\footnotetext{
${ }^{2} \mathrm{~A}$ growing literature in behavioral economics attempts to measure bias in various settings; for overviews, Allcott and Sunstein (2015), Bernheim and Rangel (2009), Bernheim and Taubinsky (2018), DellaVigna (2009), Handel and Schwartzstein (2018), Mullainathan, Schwartzstein, and Congdon (2012), and others.
} 
are assumed to be unbiased - versus another subset of "suspect" choices that may be affected by bias. This requires assumptions.

Second, measuring internalities often involves the same type of causal inference challenges that arise when estimating price elasticities, health effects, and other parameters. Third, internalities must be measured in units of dollars, as highlighted by the fact that the internality and/or externality $b$ is a vertical distance separating the demand curves on Figures 2 and 3. While much of the behavioral economics literature has focused on simply establishing the presence of some behavioral bias, behavioral welfare analysis requires that internalities be quantified in units of dollars.

As discussed earlier, imperfect information and lack of self-control are two primary reasons why consumers might not act in their own best interest. Different empirical strategies are often required to quantify different types of internalities. For imperfect information, researchers can estimate the effects of information provision, as in Allcott and Taubinsky (2015) and others. For self-control, researchers can compare choices made for consumption now versus in the future, as in Read and van Leeuwen (1998), Augenblick, Niederle, and Sprenger (2015), and others. For example, Sadoff, Samek, and Sprenger (2015) take advance orders for grocery delivery and allow people to re-optimize their choices at the time that the groceries are delivered, finding that people tend to re-optimize toward less-healthy options and that one-third of people would like to restrict their own future ability to re-optimize. However, standard "preference reversal" experiments cannot directly quantify the effects of limited self-control in dollar units. ${ }^{3}$

Alternatively, a "counterfactual normative consumer" approach can be used to measure multiple biases simultaneously, and also to quantify their effects in dollar terms. As an example of this approach, Bronnenberg, Dubé, Gentzkow, and Shapiro (2015), show that sophisticated shoppers - in their application, doctors and pharmacists - are more likely to buy generic instead of branded drugs, and they conduct welfare analysis assuming that only sophisticates' choices are welfare-relevant. Bartels (1996), Handel and Kolstad (2015), Johnson and Rehavi (2016), and Levitt and Syverson (2008) similarly compare informed to uninformed agents to identify the effects of imperfect information.

In Allcott, Lockwood, and Taubinsky (Forthcoming), we use this counterfactual normative consumer approach to measure the effect of both imperfect information and self-control on sweetened beverage consumption. Specifically, we survey Nielsen Homescan panelists to measure nutrition knowledge and perceived overconsumption of sugar-sweetened beverages, and we find that soda consumption is higher among consumers who are less informed about nutrition and who profess less self-control, even controlling for demographic variables and survey-based measures of health preferences and tastes for different drinks. The key weakness of this approach is that it requires the assumption that the conditional correlation between bias and consumption equals the causal effect of bias on consumption. Under this assumption, we predict that the average American household would consume 31 to 37 percent fewer sugar-sweetened beverages if they had perfect self-control and had the nutrition knowledge of dietitians and nutritionists. Translated into dollar terms, the estimated average marginal internality from sugar-sweetened beverage consumption is 0.91 to 2.14 cents per ounce.

\footnotetext{
${ }^{3}$ Another approach to quantifying self-control problems is to combine an outside estimate of time inconsistency from another domain with an estimate of the future private costs of sugar-sweetened beverage consumption. However, it is difficult to assess those future private costs, and the extent of time inconsistency can vary across domains.
} 


\section{Regressivity}

The progressivity or regressivity of a sin tax depends on how the internality reduction benefits and the burden of tax payments vary across the income distribution. In Allcott, Lockwood, and Taubinsky (Forthcoming), we find that internality reduction benefits are highly progressive. Lower-income people have systematically less nutrition knowledge and are more likely to self-report that they consume more sugary drinks than they think they should. While not dispositive, these facts suggest that lower-income people have larger internalities than higher-income people. Our estimated average marginal internality is about one-third larger at household incomes below $\$ 10,000$ per year compared to at household incomes above $\$ 100,000$ per year. Furthermore, low-income households reduce sugar-sweetened beverage consumption much more than high-income households when prices rise. ${ }^{4}$ Putting these two facts together implies that internality reduction benefits are highly progressive. Under conventional degrees of inequality aversion used in models of optimal income taxation, this progressivity magnifies the internality correction in the optimal tax formula by about 20 percent.

On the other hand, because low-income households consume more sugar-sweetened beverages, they pay more in tax payments. Combining the progressivity of internality reduction benefits with the regressivity of the tax payments, we find that the net benefits of a sugar-sweetened beverage tax are reasonably flat across the income distribution, and possibly highest for the lowest-income consumers. More importantly, we find that low-income people benefit substantially from sugar-sweetened beverage taxes, regardless of whether they benefit more than rich people.

\section{Substitution and Leakage}

As described earlier, the welfare effects of sugar-sweetened beverage taxes depend on whether they affect consumption of other untaxed goods that generate externalities or internalities. Various papers estimate demand systems that capture these substitution patterns between sugar-sweetened beverages and other foods and beverages. Possibly due to the challenges in data quality and variation in identification strategies, there is very little agreement in this literature. For example, Duffey, Gordon-Larsen, Shikany, Guilkey, Jacobs, and Popkin (2010) find that pizza is a strong substitute for sugar-sweetened beverages. Finkelstein, Zhen, Bilger, Nonnemaker, Farooqui, and Todd (2013) find no substitution to pizza, but statistically significant substitution to canned soup. Zhen, Finkelstein, Nonnemaker, Karns, and Todd (2014) find that canned soup is a complement to carbonated soft drinks but a substitute for sports drinks, energy drinks, and juice drinks. These conflicting and sometimes counterintuitive results highlight the difficulties in estimating substitution patterns. They may also reflect false positives from multiple hypothesis testing, as there is not an obvious reason for why pizza and canned soup are substitutes for sugary drinks.

In Allcott, Lockwood, and Taubinsky (Forthcoming), we find that diet drinks are moderate substitutes for sugar-sweetened beverages. Across a comprehensive range of other drink categories, sugary foods, and even alcohol and cigarettes, we find close to zero net substitution from sugar-sweetened beverages to other possible "sin goods." This would imply that welfare evaluations and optimal tax calculations could safely ignore substitution to other goods, unless one believes that diet drinks have material health harms.

In addition to substitution to other goods, evaluations of local taxes also need to account for substitution to sugar-sweetened beverages purchased outside of the taxed jurisdiction. Bollinger and Sexton (2019) find

\footnotetext{
${ }^{4}$ Specifically, we find very similar price elasticities, so high-income and low-income households reduce consumption by similar proportions in response to a price increase. But because low-income households consume much more, the absolute amounts of their reductions are much larger.
} 
that approximately half of purchase reductions of sugar-sweetened beverages within Berkeley appear to be substituted to retailers just outside of Berkeley. Seiler, Tuchman, and Yao (2019) also detect substitution to purchases outside of Philadelphia in response to the Philadelphia tax. This leakage reduces the welfare gains from the city-level taxes and also reduces the optimal tax rate.

\section{Pass-Through and Producer Surplus}

To ease administration and to increase tax salience, city-level sugar-sweetened beverage taxes in the U.S. are generally collected from beverage distributors that sell to retailers. A number of recent papers have estimated the extent to which these taxes are passed through into higher retail prices. Two papers studying the Philadelphia tax conclude that the tax was approximately fully passed through (Cawley, Frisvold, Hill, and Jones 2018b; Seiler, Tuchman, and Yao 2019). Six papers studying Berkeley and Boulder find less than full pass-through, implying that at least some of the incidence of these taxes is on suppliers (Bollinger and Sexton 2019; Cawley and Frisvold 2017; Cawley, Crain, Frisvold, and Jones 2018a Falbe, Rojas, Grummon, and Madsen 2015; Rojas and Wang 2017; Silver, Ng, Ryan-Ibarra, Taillie, Induni, Miles, Poti, and Popkin 2017).

Bollinger and Sexton (2019) also document how retailers' overall pricing strategies interact with a local tax on a small subset of products. First, as documented by DellaVigna and Gentzkow (Forthcoming) and Hitsch, Hortacsu, and Lin (2017), large retail chains often set uniform prices across many stores in many cities. This limits the extent to which a local cost increase from a local tax is passed through to retail prices in that area. Second, retailers often use "category pricing": for example, all two-liter bottles of regular and diet soda might have the same price. If retailers maintain equal prices for regular and diet soda and diet soda consumption involves lower internalities or externalities because it does not contain sugar, this reduces the welfare gains from a tax on sugar-sweetened beverages. This intersection between industrial organization and optimal taxation is an interesting area for further research.

\section{Putting it Together}

In Allcott, Lockwood, and Taubinsky (Forthcoming), we estimate that the socially optimal sugar-sweetened beverage tax in our model is between 1 and 2.1 cents per ounce. One can understand this as coming from the correction needed to offset the negative externality (about 0.8 cents per ounce) and internality (about 1 cent per ounce, inflated by 20 percent due to the progressivity of internality correction), with a further reduction due to the regressive incidence of the financial costs of a tax (reducing the tax by about 0.5 cents per ounce). Together, these rough estimates suggest an optimal tax of about 1.5 cents per ounce. While there is considerable uncertainty in these optimal tax estimates, the optimal tax is not zero and may be higher than the levels in most U.S. cities to date. This calculation depends on the presence of internalities: the optimal tax considering only externalities is around 0.4 cents per ounce.

\section{Some Concrete Implications of Our Economic Framework}

While there is uncertainty about some empirical parameters, economic theory and existing data imply seven principles for designing sugar-sweetened beverage taxes. The first four principles are all motivated by one deeper principle: that sin taxes should be designed to offset uninternalized harms. 


\section{Minimizing sugary drink consumption is not equivalent to optimally counter- acting externalities and internalities.}

Many public health advocates explicitly or implicitly take the perspective that policy makers' goal should be to maximize health or minimize unhealthy behaviors. It's easy to see why this can't be the right social objective. The way to maximize health is to ban any sugary or fatty food or drink, including sugary drinks, red meat, dessert, etc. Such a ban would preclude any enjoyment that people get from eating steak or dessert, and it's not clear where to draw the line on what foods or drinks to ban.

The economic framework presented in this paper instead focuses on maximizing social welfare, and provides a principled approach that trades off health-related externalities and internalities with consumer surplus, producer surplus, and government revenues. The framework highlights that unhealthy behaviors do not necessarily merit policy intervention, as they could simply reflect the fact that people enjoy eating steak and dessert. Sin taxes are justified only to the extent that they offset uninternalized externalities or internalities.

\section{It is most efficient to target policies to reduce consumption among people generating the largest externalities and internalities.}

Consumption by different people may involve larger or smaller externalities and internalities, perhaps due to differences in self-control, nutrition knowledge, and health insurance coverage. Ideally, policies would be targeted to reduce consumption more among people with larger externalities and internalities. For example, if internalities and externalities are largest among children-perhaps due to limited self-control, or because their consumption generates lifelong habits - then very high taxes or bans on sugar-sweetened beverages in schools may be justified.

\section{It is more efficient to tax grams of sugar, rather than ounces of liquid.}

Most sugar-sweetened beverage taxes are structured as a per-ounce tax on any drink with added sugar. That means that drinks with high and low amounts of added sugar are taxed at the same rate. From the perspective of the theoretical rationale for sugary drink taxes, this structure makes little sense. It's the sugar in the drinks, not the amount of liquid, that harms our health. Therefore, drinks containing more sugar generate greater externalities and probably greater internalities.

Scaling the tax with the amount of sugar instead of the amount of liquid that comes with the sugar encourages consumers to switch to lower-sugar drinks and also encourages producers to reduce sugar content. Using economic and epidemiological models, we estimate that taxing sugar-sweetened beverages based on sugar content instead of volume would boost a tax's health benefits by 43 percent, helping people around the world to lose nearly 200 million pounds (Grummon, Lockwood, Taubinsky, and Allcott, 2019a). Other research arrives at qualitatively similar conclusions about the gains from taxing sugar content instead of volume (Francis, Marron, and Reuben 2016; Zhen, Brissette, and Ruff 2014). ${ }^{5}$

\footnotetext{
${ }^{5}$ The United Kingdom and several other countries approximate sugar taxes through tiered systems that impose a higher volumetric tax for drinks with higher sugar content, but this still falls short of the ideal of setting taxes proportional to uninternalized harms.
} 


\section{Taxing diet drinks and fruit juice is efficient if and only if they also cause uninternalized health harms.}

Even if restricted to one cent per ounce volumetric taxes, policy makers must decide what drinks should be included in sugary drink taxes. The Philadelphia and erstwhile Cook County taxes also include diet drinks, on the grounds that this raises more revenues and also makes the tax less regressive because higher-income people buy more diet drinks. Including diet drinks would be justified by economic principles only if the externalities and internalities from diet drinks are as large as those from non-diet drinks. The evidence presented earlier suggests that diet drinks are less harmful.

All existing sugary drink taxes exclude 100 percent fruit juice, despite arguments by Wojcicki and Heyman (2012), Gill and Sattar (2014), and some other public health experts that the naturally occurring sugar in fruit juice may be equally harmful as the added sugar in soft drinks. Exempting fruit juice from a beverage

tax is justified only if the positive externalities and internalities from the additional vitamins and nutrients offset the negative externalities and internalities from the sugar.

\section{The regressivity of the tax depends on who has larger internalities, not just who pays more in taxes.}

Some people argue that sugar-sweetened beverage taxes are regressive, because low-income people buy more of these beverages and will thus pay more in taxes. As we have discussed, however, what really matters in a standard economic model is not how much low-income people pay in taxes, but how much a tax benefits or harms them overall. In Allcott, Lockwood, and Taubinsky (Forthcoming), we estimate that low-income people enjoy a disproportionate share of the internality reduction benefits, because they both have larger internalities in this domain and reduce consumption more in response to a tax. Overall, our results suggest that in a standard economic model low-income people benefit substantially from sugar-sweetened beverage taxes, and they may even benefit more than rich people.

\section{Statewide implementation of taxes reduces the efficiency costs of leakage.}

All of the current sugar-sweetened beverage taxes in the U.S. have been implemented by individual cities. Evidence suggests that the benefits of city-level taxes are diminished because consumers avoid these taxes by purchasing outside of the city. Implementing the taxes over larger geographic areas, for example at the state level, would reduce leakage. Such geographic integration can also help to reduce the importance of compliance and administrative costs. However, the existence of externalities and internalities suggest that city-level taxes may still be better than no taxes at all.

\section{SSB taxes are likely welfare enhancing in our theoretical framework.}

Our read of the evidence is that sugar-sweetened beverage consumption likely imposes externalities on the health system and internalities due to imperfect nutrition knowledge and self-control problems. In Allcott, Lockwood, and Taubinsky (Forthcoming), the model and parameter estimates imply that the social welfare benefits from implementing the optimal tax nationwide (relative to having zero tax) are between $\$ 2.4$ billion and $\$ 6.8$ billion per year. These gains would be substantially larger if the tax rate were to scale with sugar content. 
Of course, such calculations require strong assumptions and depend on uncertain empirical estimates, in particular with respect to internalities and externalities. We therefore emphasize that much more empirical work is needed. Furthermore, sugar-sweetened beverage taxes are not a panacea - they will not, by themselves, solve the obesity epidemic in America or elsewhere. But sin taxes have proven to be a feasible and effective policy instrument in other domains, and parameter estimates suggest that they are likely welfare-enhancing in our theoretical framework. 


\section{References}

Allcott, Hunt, Benjamin B. Lockwood, and Dmitry Taubinsky. Forthcoming. "Regressive Sin Taxes, with an Application to the Optimal Soda Tax." Quarterly Journal of Economics .

Allcott, Hunt and Cass R. Sunstein. 2015. "Regulating Internalities." Journal of Policy Analysis and Management 34 (3):698-705.

Allcott, Hunt and Dmitry Taubinsky. 2015. "Evaluating Behaviorally-Motivated Policy: Experimental Evidence from the Lightbulb Market." American Economic Review 105 (8):2501-2538.

Andreyeva, Tatiana, Michael W. Long, and Kelly D. Brownell. 2010. "The Impact of Food Prices on Consumption: A Systematic Review of Research on the Price Elasticity of Demand for Food." American Journal of Public Health 100 (2):216-222.

Atkinson, Anthony B and J.E. Stiglitz. 1976. "The Design of Tax Structure: Direct Versus Indirect Taxation." Journal of Public Economics 6 (1-2):55-75.

Augenblick, Ned, Muriel Niederle, and Charles Sprenger. 2015. "Working Over Time: Dynamic Inconsistency in Real Effort Tasks." Quarterly Journal of Economics 130 (3):1067-1115.

Bartels, Larry M. 1996. "Uninformed Votes: Information Effects in Presidential Elections." American Journal of Political Science 40 (1):194-230.

Bernheim, B. Douglas. 2016. "The Good, the Bad, and the Ugly: A Unified Approach to Behavioral Welfare Economics." Journal of Cost Benefit Analysis 7 (1):12-68.

Bernheim, B. Douglas and Antonio Rangel. 2009. "Beyond Revealed Preference: Choice-Theoretic Foundations for Behavioral Welfare Economics." Quarterly Journal of Economics 124 (1):51-104.

Bernheim, B. Douglas and Dmitry Taubinsky. 2018. "Behavioral Public Economics." In The Handbook of Behavioral Economics, vol. 1, edited by B. Douglas Bernheim, Stefano DellaVigna, and David Laibson. New York: Elsevier.

Bhattacharya, Jay and M. Kate Bundorf. 2009. "The Incidence of the Healthcare Costs of Obesity." Journal of Health Economics 28 (3):649-658.

Bhattacharya, Jay and Neeraj Sood. 2011. "Who Pays for Obesity?" Journal of Economic Perspectives $25(1): 139-158$.

Bollinger, Bryan, Phillip Leslie, and Alan Sorensen. 2011. "Calorie Posting in Chain Restaurants." American Economic Journal: Economic Policy 3 (1):91-128.

Bollinger, Bryan and Steven Sexton. 2019. "Local Excise Taxes, Sticky Prices, and Spillovers: Evidence from Berkeley's Soda Tax." Working Paper.

Bronnenberg, Bart, Jean-Pierre Dubé, Matthew Gentzkow, and Jesse Shapiro. 2015. "Do Pharmacists Buy Bayer? Sophisticated Shoppers and the Brand Premium." Quarterly Journal of Economics 130 (4):16691726. 
Cantor, Jonathan, Alejandro Torres, Courtney Abrams, and Brian Elbel. 2015. "Five years later: awareness of New York City's calorie labels declined, with no changes in calories purchased." Health Affairs 34 (11):1893-1900.

Cawley, John, Chelsea Crain, David Frisvold, and David Jones. 2018a. "The Pass-Through of the Largest Tax on Sugar-Sweetened Beverages: The Case of Boulder, Colorado." NBER Working Paper .

Cawley, John, David Frisvold, Anna Hill, and David Jones. 2018b. "The Impact of the Philadelphia Beverage Tax on Prices and Product Availability." NBER Working Paper .

_. 2018c. "The Impact of the Philadelphia Beverage Tax on Purchases and Consumption by Adults and Children." NBER Working Paper.

Cawley, John and David E. Frisvold. 2017. "The Pass-Through of Taxes on Sugar-Sweetened Beverages to Retail Prices: The Case of Berkeley, California." Journal of Policy Analysis and Management 36 (2):303326.

Cawley, John and Chad Meyerhoefer. 2012. "The Medical Care Costs of Obesity: An Instrumental Variables Approach." Journal of Health Economics 31 (1):219-230.

de Ruyter, Janne C., Margreet R. Olthof, Jacob C. Seidell, and Martijn B. Katan. 2012. "A Trial of SugarFree or Sugar-Sweetened Beverages and Body Weight in Children." New England Journal of Medicine 367 (15):1397-1406.

DellaValle, Diane M., Liane S. Roe, and Barbara J. Rolls. 2005. "Does the Consumption of Caloric and Non-Caloric Beverages with a Meal Affect Energy Intake?" Appetite 44 (2):187-193.

DellaVigna, Stefano. 2009. "Psychology and Economics: Evidence from the Field." Journal of Economic Literature 47 (2):315-372.

DellaVigna, Stefano and Matthew Gentzkow. Forthcoming. "Uniform Pricing in US Retail Chains." Quarterly Journal of Economics .

Dubois, Pierre, Rachel Griffith, and Martin O'Connell. 2017. "How Well-Targeted Are Soda Taxes?" Working Paper.

Duffey, Kiyah J., Penny Gordon-Larsen, James M. Shikany, David Guilkey, David R. Jacobs, and Barry M. Popkin. 2010. "Food Price and Diet and Health Outcomes." Archives of Internal Medicine 170 (5):420-426.

Ebbeling, Cara B., Henry A. Feldman, Virginia R. Chomitz, Tracy A. Antonelli, Steven L. Gortmaker, Stavroula K. Osganian, and David S. Ludwig. 2012. "A Randomized Trial of Sugar-Sweetened Beverages and Adolescent Body Weight." New England Journal of Medicine 367 (15):1407-1416.

Falbe, Jennifer, Nadia Rojas, Anna Grummon, and Kristine A Madsen. 2015. "Higher Retail Prices of SugarSweetened Beverages 3 Months After Implementation of an Excise Tax in Berkeley, California." American Journal of Public Health 105 (11):2194-2201.

Finkelstein, Eric A., Chen Zhen, Marcel Bilger, James Nonnemaker, Assad M. Farooqui, and Jessica E. Todd. 2013. "Implications of a Sugar-Sweetened Beverage (SSB) Tax When Substitutions to Non-Beverage Items are Considered." Journal of Health Economics 32 (1):219-239. 
Fletcher, Jason M., David E. Frisvold, and Nathan Teft. 2010. "The Effects of Soft Drink Taxes on Child and Adolescent Consumption and Weight Outcomes." Journal of Public Economics 94 (11-12):967-974.

Flood, Julie E., Liane S. Roe, and Barbara J. Rolls. 2006. "The Effect of Increased Beverage Portion Size on Energy Intake at a Meal." Journal of the Academy of Nutrition and Dietetics 106 (12):1984-1990.

Fontaine, Kevin R., David T. Redden, Chenxi Wang, Andrew O. Westfall, and David B. Allison. 2003. "Years of Life Lost Due to Obesity." Journal of the American Medical Association 289 (2):187-193.

Francis, Norton, Donald Marron, and Kim Reuben. 2016. "The Pros and Cons of Taxing Sweetened Beverages Based on Sugar Content." Urban Institute Research Report URL https://www.taxpolicycenter.org/sites/default/files/publication/136861/pros_and_cons_ of_taxing_sweetened_beverages_based_on_sugar_content.pdf.

Fung, Teresa T., Vasanti Malik, Kathryn M. Rexrode, JoAnn E. Manson, Walter C. Willett, and Frank B. Hu. 2009. "Sweetened Beverage Consumption and Risk of Coronary Heart Disease in Women." The American Journal of Clinical Nutrition 89 (4):1037-1042.

Gill, Jason MR and Naveed Sattar. 2014. "Fruit juice: just another sugary drink?" The Lancet 2 (6):444-446.

Global Food Research Program (GFRP). 2019. "Sugary Drink Taxes Around the World." URL https: //www.dropbox.com/s/bqbj501wgocor24/UNCGFRP_SSB_tax_maps.pdf?dl=0.

Gruber, Jonathan and Botond Köszegi. 2004. "Tax Incidence When Individuals Are Time-Inconsistent: The Case of Cigarette Excise Taxes." Journal of Public Economics 88 (9-10):1959-1987.

Grummon, Anna, Benjamin B. Lockwood, Dmitry Taubinsky, and Hunt Allcott. 2019a. "Designing Better Sugary Drink Taxes: How to Lose 200 Million Pounds with One Simple Trick." Working Paper .

Grummon, Anna, Lindsey Smith Tallie, Shelley D Golden, Marissa G Hall, Leah M Ranney, and Noel Brewer. 2019b. "Impact of sugar-sweetened beverage health warnings on beverage purchases: A randomized controlled trial." Working Paper.

Handel, Benjamin and Joshua Schwartzstein. 2018. "Frictions or Mental Gaps: What's Behind the Information We (Don't) Use and When Do We Care?" Journal of Economic Perspectives 32 (1):155-178.

Handel, Benjamin R and Jonathan T Kolstad. 2015. "Health Insurance for 'Humans': Information Frictions, Plan Choice, and Consumer Welfare." American Economic Review 105 (8):2449-2500.

Hitsch, Günter J., Ali Hortacsu, and Xiliang Lin. 2017. "Prices and Promotions in U.S. Retail Markets: Evidence from Big Data." Working Paper.

Imamura, Fumiaki, Laura O'Connor, Zheng Ye, Jaakko Mursu, Yasuaki Hayashino, Shilpa N Bhupathiraju, and Nita G Forouhi. 2015. "Consumption of sugar sweetened beverages, artificially sweetened beverages, and fruit juice and incidence of type 2 diabetes: systematic review, meta-analysis, and estimation of population attributable fraction." British Medical Journal 351:h3576.

Johnson, Erin M. and M. Marit Rehavi. 2016. "Physicians Treating Physicians: Information and Incentives in Childbirth." American Economic Journal: Economic Policy 8 (1):115-141. 
Levitt, Steven D. and Chad Syverson. 2008. "Market Distortions when Agents are Better Informed: The Value of Information in Real Estate Transactions." Review of Economics and Statistics 90 (4):599-611.

Long, Michael W., Steven L. Gortmaker, Zachary J. Ward, Stephen C. Resch, Marj L. Moodie, Gary Sacks, Boyd A. Swinburn, Rob C. Carter, and Y. Claire Wang. 2015. "Cost Effectiveness of a Sugar-Sweetened Beverage Excise Tax in the U.S." American Journal of Preventive Medicine 49 (1):112-123.

Loughead, Katherine. 2018. "Sales Taxes on Soda, Candy, and Other Groceries, 2018." URL https: //files.taxfoundation.org/20180706104150/Tax-Foundation-FF598-Groceries-Soda-Candy.pdf.

Ludwig, David S. 2002. "The Glycemic Index: Physiological Mechanisms Relating to Obesity, Diabetes, and Cardiovascular Disease." Journal of the American Medical Association 287 (18):2414-2423.

Malik, Vasanti S., An Pan, Walter C. Willett, and Frank B. Hu. 2013. "Sugar-Sweetened Beverages and Weight Gain in Children and Adults: A Systematic Review and Meta-Analysis." The American Journal of Clinical Nutrition 98 (4):1084-1102.

Malik, Vasanti S., Barry M. Popkin, George A. Bray, Jean-Pierre Després, Walter C. Willett, and Frank B. Hu. 2010. "Sugar-Sweetened Beverages and Risk of Metabolic Syndrome and Type 2 Diabetes: a MetaAnalysis." Diabetes Care 33 (11):2477-2483.

Mattes, Richard D., J.M. Shikany, K.A. Kaiser, and D.B. Allison. 2011. "Nutritively Sweetened Beverage Consumption and Body Weight: A Systematic Review and Meta-Analysis of Randomized Experiments." Obesity Reviews 12 (5):346-365.

Moran, Alyssa J and Christina A Roberto. 2018. "Health warning labels correct Parents' misperceptions about sugary drink options." American Journal of Preventive Medicine 55 (2):e19-e27.

Mourao, D. M., J. Bressan, W. W. Campbell, and R. D. Mattes. 2007. "Effects of Food Form on Appetite and Energy Intake in Lean and Obese Young Adults." International Journal of Obesity 31 (11):1688-1695.

Mozaffarian, Dariush, Tao Hao, Eric B. Rimm, Walter C. Willett, and Frank B. Hu. 2011. "Changes in Diet and Lifestyle and Long-Term Weight Gain in Women and Men." New England Journal of Medicine 364 (25):2392-2404.

Mullainathan, Sendhil, Joshua Schwartzstein, and William J Congdon. 2012. "A Reduced-Form Approach to Behavioral Public Finance." Annual Review of Economics 4 (1):511-540.

Pan, An and Frank B Hu. 2011. "Effects of carbohydrates on satiety: differences between liquid and solid food." Current Opinion in Clinical Nutrition \& Metabolic Care 14 (4):385-390.

Pigou, Arthur Cecil. 1920. The Economics of Welfare.

Popkin, Barry M. and Corinna Hawkes. 2016. "The Sweetening of the Global Diet, Particularly Beverages: Patterns, Trends and Policy Responses for Diabetes Prevention." Lancet Diabetes Endocrinology 4 (2):174186.

Powell, Lisa M., Jamie F. Chriqui, Tamkeen Khan, Roy Wada, and Frank J. Chaloupka. 2013. "Assessing the Potential Effectiveness of Food and Beverage Taxes and Subsidies for Improving Public Health: A Systematic Review of Prices, Demand and Body Weight Outcomes." Obesity Reviews 14 (2):110-128. 
Raben, Anne, BenteK Møller, Anne Flint, TatjanaH Vasilaras, A. Christina Møller, Jens Juul Holst, and Arne Astrup. 2011. "Increased Postprandial Glycaemia, Insulinemia, and Lipidemia after 10 Weeks' SucroseRich Diet Compared to an Artificially Sweetened Diet: A Randomised Controlled Trial." Food \& Nutrition Research 55 (1):5961.

Read, Daniel and Barbara van Leeuwen. 1998. "Predicting Hunger: The Effects of Appetite and Delay on Choice." Organizational Behavior and Human Decision Processes 76 (2):189-205.

Rees-Jones, Alex and Kyle Rozema. 2018. "Price Isn't Everything: Behavioral Response around Changes in Sin Taxes." Working Paper.

Rojas, Christian and Emily Wang. 2017. "Do Taxes for Soda and Sugary Drinks Work? Scanner Data Evidence from Berkeley and Washington." Working Paper.

Sadoff, Sally, Anya Samek, and Charles Sprenger. 2015. "Dynamic Inconsistency in Food Choice: Experimental Evidence from a Food Desert." Working Paper.

Saez, Emmanuel and Stefanie Stantcheva. 2016. "Generalized Social Welfare Weights for Optimal Tax Theory." American Economic Review 106 (1):24-45.

Santos, F. L., S. S. Esteves, A. da Costa Pereira, W. S. Yancy Jr, and J. P. L. Nunes. 2012. "Systematic Review and Meta-Analysis of Clinical Trials of the Effects of Low-Carbohydrate Diets on Cardiovascular Risk Factors." Obesity Reviews 13 (11):1048-1066.

Schulze, Matthias B., JoAnn E. Manson, David S. Ludwig, Graham A. Colditz, Meir J. Stampfer, Walter C. Willett, and Frank B. Hu. 2004. "Sugar-Sweetened Beverages, Weight Gain, and Incidence of Type 2 Diabetes in Young and Middle-Aged Women." Journal of the American Medical Association 292 (8):927934.

Seiler, Stephan, Anna Tuchman, and Song Yao. 2019. "The Impact of Soda Taxes: Pass-through, Tax Avoidance, and Nutritional Effects." Working Paper.

Silver, Lynn D., Shu Wen Ng, Suzanne Ryan-Ibarra, Lindsey Smith Taillie, Marta Induni, Donna R. Miles, Jennifer M. Poti, and Barry M. Popkin. 2017. "Changes in Prices, Sales, Consumer Spending, and Beverage Consumption One Year After a Tax on Sugar-Sweetened Beverages in Berkeley, California, US: A BeforeAnd-After Study." PLoS: Medicine 14 (4).

Taylor, Rebecca, Scott Kaplan, Sofia B Villas-Boas, and Kevin Jung. 2016. "Soda Wars: Effect of a Soda Tax Election on Soda Purchases." Working Paper.

Te Morenga, Lisa A., Alex J. Howatson, Rhiannon M. Jones, and Jim Mann. 2014. "Dietary Sugars and Cardiometabolic Risk: Systematic Review and Meta-Analyses of Randomized Controlled Trials of the Effects on Blood Pressure and Lipids." The American Journal of Clinical Nutrition 100 (1):65-79.

Vartanian, Lenny R., Marlene B. Schwartz, and Kelly D. Brownell. 2007. "Effects of Soft Drink Consumption on Nutrition and Health: A Systematic Review and Meta-Analysis." American Journal of Public Health 97 (4):667-675.

Wang, Y Claire, Pamela Coxson, Yu-Ming Shen, Lee Goldman, and Kirsten Bibbins-Domingo. 2012. "A Penny-Per-Ounce Tax on Sugar-Sweetened Beverages Would Cut Health and Cost Burdens of Diabetes." Health Affairs 31 (1):199-207. 
Wojcicki, Janet M and Melvin B Heyman. 2012. "Reducing Childhood Obesity by Eliminating 100\% Fruit Juice." American Journal of Public Health 109 (9):1630-1633.

Xi, Bo, Yubei Huang, Kathleen Heather Reilly, Shuangshuang Li, Ruolong Zheng, Maria T. Barrio-Lopez, Miguel A. Martinez-Gonzalez, and Donghao Zhou. 2015. "Sugar-Sweetened Beverages and Risk of Hypertension and CVD: A Dose-Response Meta-Analysis." British Journal of Nutrition 113 (5):709-717.

Yong, Pierre L., John Bertko, and Richard Kronick. 2011. "Actuarial Value and Employer-Sponsored Insurance."

Zhen, Chen, Ian F Brissette, and Ryan Richard Ruff. 2014. "By Ounce or By Calorie: The Differential Effects of Alternative Sugar-Sweetened Beverage Tax Strategies." 96 (4):1070-1083.

Zhen, Chen, Eric A. Finkelstein, James Nonnemaker, Shawn Karns, and Jessica E. Todd. 2014. "Predicting the Effects of Sugar-Sweetened Beverage Taxes on Food and Beverage Demand in a Large Demand System." American Journal of Agricultural Economics 96 (1):1-25. 